\title{
Inventory Optimization Using Simulation Approach
}

\author{
Nuridawati Baharom ${ }^{1 *}$, Pa'ezah Hamzah ${ }^{2}$ \\ ${ }^{1,2}$ Faculty of Computer and Mathematical Sciences, Universiti Teknologi MARA, Arau, Perlis, Malaysia
}

Corresponding author: *nuridawati@perlis.uitm.edu.my

Received Date: 31 August 2018

Accepted Date: 17 October 2018

\begin{abstract}
Inventory creates a significant cost to a firm in the form of the ordering cost, shortage cost, holding cost and also the cost of the goods itself. Managing inventory is always a big challenge for firms in order to balance these operating costs and maintain customer's service. In this paper, a case study of an electronic manufacturing firm was used to illustrate the use of the Monte Carlo simulation to improve the current inventory system for sensor cable. A simulation model mimicking the current inventory system was developed, and used to study the current system and alternative reorder point policies. Various reorder points were experimented to determine the reorder policy that results in the lowest average total inventory cost per week. The simulation experiments allow the decision maker to make good purchasing decisions in order to avoid ordering excessive raw materials, which lead to higher inventory cost to the company.
\end{abstract}

Keywords: Inventory, Optimization, Monte Carlo Simulation

\section{INTRODUCTION}

Almost all business organizations hold inventory. Inventory exists in the form of stock of raw materials, work-in-process (WIP), finished goods and maintenance and repair supplies. These forms of inventory are classified as manufacturing inventory, and in services, inventory generally refers to the tangible goods to be sold and the supplies needed to provide the service (Jacobs \& Chase, 2010). Firms keep their inventory on hand to ensure smooth production process and give better services to customer. However, inventory creates a significant cost to a firm. Larger inventory leads to higher invested capital. Thus, it is crucial for operations managers to keep a reasonable amount of inventory to minimize costs.

Since customer demand is not known with certainty and may vary, it is important for a firm to save additional stocks called safety or buffer stocks to avoid shortages (Taylor, 2004). This practice will certainly prevent lost of sales due to shortages of raw materials. On the other hand, a firm often makes large purchases above their requirements to take advantage of quantity discounts. Purchasing in larger quantities does not only reduce the cost of goods, but also cut down delivery costs (Heizer \& Render, 2011). However, improper planning on the amount of safety stocks may lead to excess of inventory. Excess inventory is a waste and is considered as a loss to the firm.

Inventory management is an important function to every firm. Having the right inventory at the right time will help the company manage uncertainties. Thus, there must be a system or policy to control the inventory and determine how much stock to keep, when to replenish the stock and how large should the order size be. In order to develop the best ordering policy, firms have to consider the variation in customer demand and lead time. This can be done using computer simulation whereby this approach is able to capture system dynamic using probability distribution and could minimize the risk of changes in inventory policy by performing what-if simulation (Chang \& Makatsoris, 2001). There are many simulation studies conducted to identify optimal inventory policies (Al-Harkan \& Hariga, 2007; Setamanit, 2010; Abuizam, 2011; 
Setamanit, 2011). Using simulation, the effect of different configuration of inventory control systems can be investigated (Al-Harkan \& Hariga, 2007; Setamanit, 2010; Setamanit, 2011).

In this study, simulation modelling via Excel spreadsheet that imitates the current inventory management system at an electronic manufacturing firm was developed. The Monte Carlo Simulation approach was applied as demand and lead time were uncertain. The simulation experiments involved varying the reorder points to identify the effect on costs.

The rest of this paper is organized as follows: Section 2 describes the background of the case study, the simulation model and verification and validation part. Section 3 presents the simulation results of the current system. Section 4 shows the simulation experiments using different reorder points that result in the lowest average total inventory cost per week. Lastly, Section 5 gives the conclusions and recommendations of the study.

\section{CASE STUDY BACKGROUND}

This research was carried out to study the current inventory system at an electronic product manufacturing firm which operates 52 weeks a year. The firm maintains five types of inventory: raw materials, work-inprogress (WIP), consumables, spare parts and finished goods. The raw material inventory is considered the most important as the items are required for production. However, since there are thousands of raw materials in inventory, it is difficult for the firm to closely monitor all the items.

A list of raw materials which were of the management's concern was identified in an interview with the purchasing manager. However, this study focuses on the inventory policy of only one item from the list, which is a sensor cable. The sensor cable is one of the most expensive inventory items, but it is a highly required raw material. The availability of the sensor cable is crucial, but the high cost is a big concern to the firm. Accordingly, the management wishes to find a suitable inventory policy to optimize the amount of inventory in order to reduce cost.

Currently, the firm's inventory system is updated based on the order for raw materials. At the beginning of each week, a planner reviews the weekly demand and forecast the quantity of raw materials needed for a particular week and the next few weeks. Then, the forecast for raw materials are uploaded into the company's inventory management system. The inventory level is reviewed and monitored using the system. When inventory on hand drops to a particular level or reorder point, the ordering system notifies the buyers to place order for the suppliers. Buyers make purchase of raw materials up to the maximum quantity allowed. This is called order-up-to-level.

\section{Data Collection}

There are nine types of data collected in this study. These are the item's unit cost, shortage cost, ordering cost, reorder point, order-up-to-level, customer weekly demand, initial inventory level, order release date and order receipt date.

The sensor cable costs RM967.79 each and is ordered from Singapore. According to the purchasing manager, the ordering cost is RM977.34 per order. Whenever there are shortages, the firm buys the units short from another supplier. However, the cost is $13 \%$ higher than the cost from the regular supplier.

Holding cost information was not available, but this study uses an annual rate estimate of $25 \%$. This figure was applied based on an earlier study by (Johnson \& Wood, 1986). This is also supported by (Richardson, 
1995) who estimated that holding cost is about $25 \%$ to $55 \%$ of unit cost per year. Thus, for simplification purposes, the annual holding cost rate was assumed to be $25 \%$ of the unit cost. Since the data of this study were measured on a weekly basis, the holding cost was also computed accordingly, and set at RM4.65 per unit per week.

The current reorder point and the order-up-to-level quantity for the current inventory system were 104 units and 504 units, respectively. An order placed at the beginning of a week takes about 3 to 6 weeks to arrive.

Both demand and lead time were uncertain. ARENA Input Analyzer was used to identify their distributions. The weekly demand was found to be normally distributed with mean 114 units and standard deviation 21.5. The lead time, on the other hand, follow the triangular distribution with parameter set; minimum 3, mode 3.99 and maximum 6 .

\section{Simulation Model}

This study uses the simulation approach to model the current inventory system for the manufacturing firm. The main objective of this study is to propose a suitable inventory policy that is capable of reducing the total inventory cost for the sensor cable. The focus is on finding the best reorder point. The flow of the simulation process is as illustrated in Figure 1. At the beginning of the week, if order has arrived, the current inventory level will increase by quantity ordered. If no order, random number will generate weekly demand based on normal probability distribution. Shortages will be recorded if demand is greater than beginning inventory. Next, order will be place if there are no outstanding orders. Orders will be received according to lead time generated using triangular distribution. On the other hand, if beginning inventory is sufficiently meeting the demand, the simulation system will compute ending inventory. If ending inventory less than reorder point, order will be placed.

To search for the best reorder point, different values of reorder point were experimented, and the results were compared with the management's current reorder point policy of 104 units. Each simulation experiment on a reorder point was run for 1,000 weeks. The performance of each reorder point was measured from the average total inventory cost per week, which was calculated at the end of simulation run. The average total cost per week is the sum of three major components, the weekly averages of ordering cost, holding cost, and shortage cost (Kelton, Sadowski \& Sturrock, 2007) as follows:

- Average ordering cost per order $\left(O_{c}\right)$. A cost of RM977.34 will be incurred each time an order is placed. If no order is placed, the ordering cost will be zero. The average ordering cost per week is computed by dividing the sum of ordering cost by the number of simulated week (1,000 weeks).

- Average holding cost per week $\left(H_{c}\right)$. This cost will be incurred whenever there are items physically in inventory. The holding cost per unit per week is RM4.65. The average holding cost per week, on the other hand, is computed by dividing the sum of holding cost by the number of simulated week ( 1,000 weeks).

- Average shortage cost $\left(S_{c}\right)$. Shortage will occur whenever the customer demand is higher than the on-hand inventory. This unfulfilled order will incur some cost to the company. The average shortage cost per week is equal to the sum of shortage cost divided by the number of simulated week (1,000 weeks).

The best reorder point is the one that results in the lowest average total inventory cost per week. Figure 1 shows the steps in inventory simulation while Figure 2 gives an overview of the simulation experiment. 


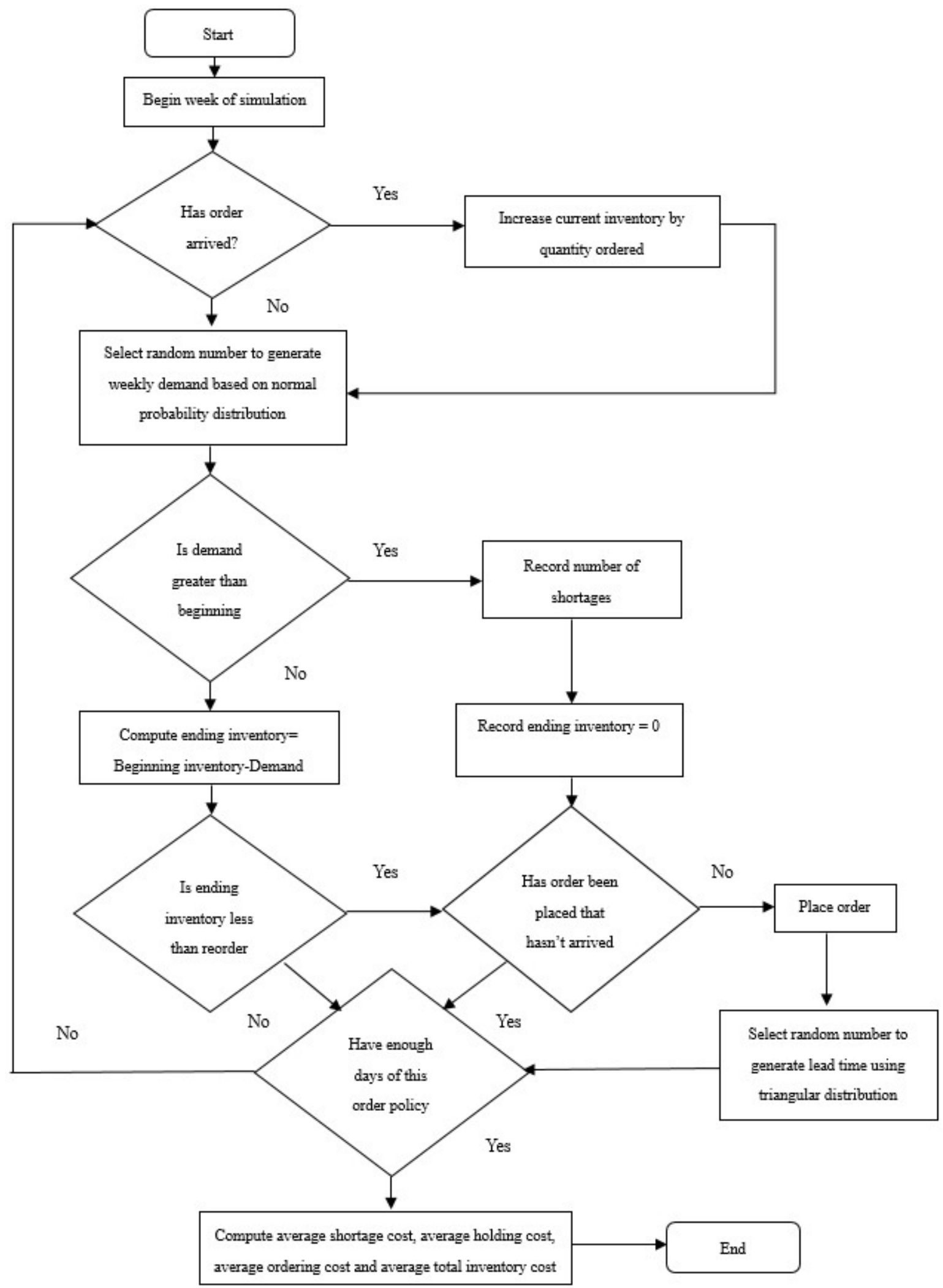

Figure 1: Flow Diagram of Inventory Simulation 


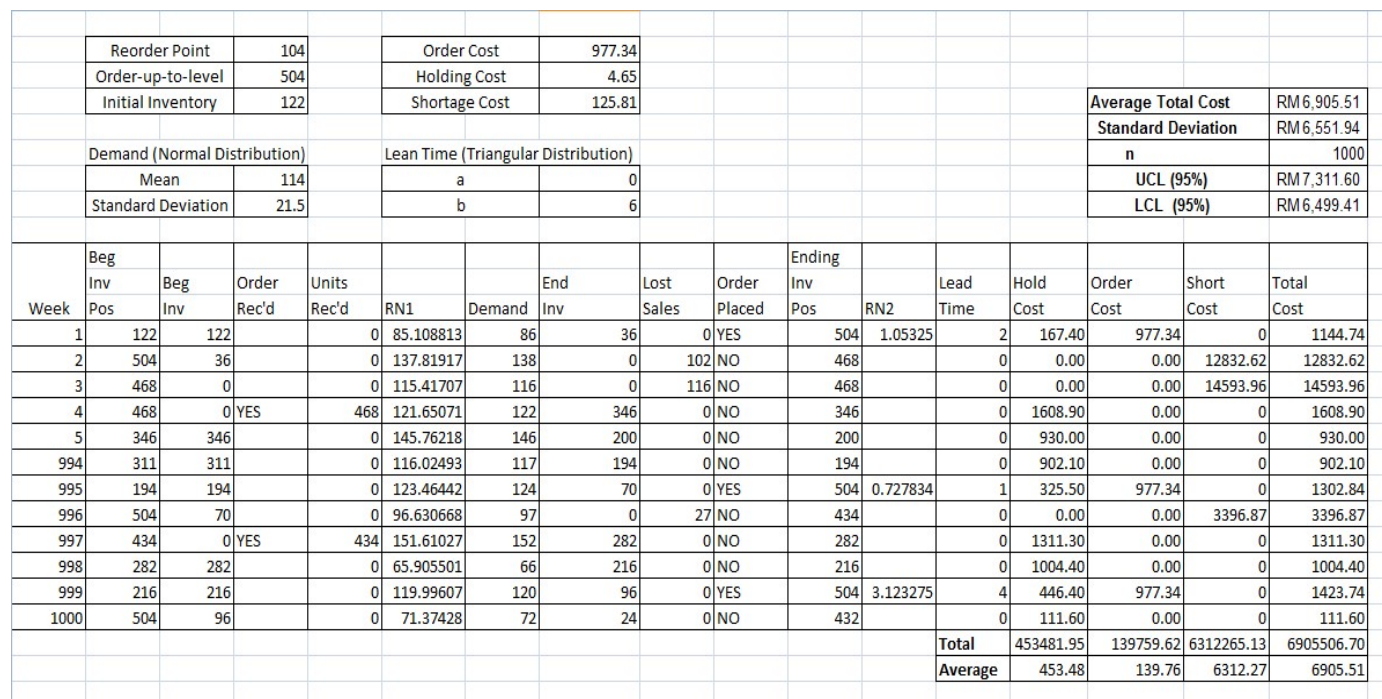

Figure 2: Overview of a simulation experiment

\section{Model Verification and Validation}

There are many techniques to verify a simulation model. One of the techniques suggested by Law \& Kelton is by computing the sample mean and sample variance for each input variable and compares them with the historical mean and variance. In this study, an analysis of variance (ANOVA) test was performed to compare the actual average demand with the simulated value.

The SPSS computer output for the ANOVA test as shown in Table 1 indicates that the $p$-value is greater than 0.05 . Accordingly, there is not enough evidence to reject the null hypothesis that the actual average demand and the simulated average are not significant. Hence, the simulated average demand is deemed acceptable.

Table 1: SPSS Output on ANOVA Test

\begin{tabular}{|l|l|l|l|l|l|}
\hline \multirow{2}{*}{} & \multicolumn{5}{|c|}{ ANOVA } \\
\cline { 2 - 6 } & Sum of Squares & $\mathrm{df}$ & $\begin{array}{l}\text { Mean } \\
\text { Square }\end{array}$ & $\mathrm{F}$ & Sig. \\
\hline Between Groups & 1.286 & 1 & 1.286 & .002 & .962 \\
\hline Within Groups & 14362.143 & 26 & 552.390 & & \\
\hline Total & 14363.429 & 27 & & \\
\hline
\end{tabular}

In the next step, a validation process was implemented to further check on the results. One of the most commonly used tools for the analysis of the statistical validity of simulation results is the confidence limit (Taylor, 2004). This study use $95 \%$ confidence limit. Confidence limits can easily be generated using Excel spreadsheet.

$$
\begin{aligned}
& \text { upper confidence limit }=\bar{x}+1.96(\mathrm{~s} / \sqrt{n}) \\
& \text { lower confidence limit }=\bar{x}-1.96(\mathrm{~s} / \sqrt{n})
\end{aligned}
$$


where $\bar{x}$ is the mean and $s$ is the sample standard deviation from a sample of size $n$ from any population. The confidence limits for the average total inventory cost per week were calculated using formulas (1) and (2).

The results for a sample size $(n)$ of 1,000 simulation runs are presented in Table 2. Thus, it can be concluded with $95 \%$ confident that the true average total inventory cost per week for the population is between RM6,499.41 and RM7,311.60.

After the verification and validation processes were completed, the researchers were confident enough to use the simulation model to proceed to the next stage of this study which was model experimentation.

Table 2: Confidence Limits for Average Total Inventory Cost

\begin{tabular}{|l|c|}
\hline \multicolumn{1}{|c|}{ Item } & Cost \\
\hline Average Total Inventory Cost per week & $\mathrm{RM} 6,905.51$ \\
\hline Standard Deviation & $\mathrm{RM} 6,551.94$ \\
\hline Upper confidence limit (UCL) & $\mathrm{RM} 7,311.60$ \\
\hline Lower confidence limit (LCL) & $\mathrm{RM} 6,499.41$ \\
\hline
\end{tabular}

\section{CASE STUDY RESULTS}

Based on the simulation of the current system, the average total inventory cost per week for the reorder point of 104 units is RM6,905.51. Simulation experiments were run to determine the reordering policy that results in the lowest average total inventory cost per week using different values of reorder point to search for the one giving the lowest average total inventory cost per week. This simulation was run for 1,000 weeks.

The optimal order quantity can be calculated using the Economic Order Quantity (EOQ) formula and the following parameters:

Annual Demand $(D)=114$ units/week $\times 52$ weeks/year $=5,928$ units/year

Holding Cost $(H C)=R M 4.65 /$ unit/week $\times 52$ weeks/year $=$ RM241.80/units/year

Ordering Cost $(O C)=R M 977.34 /$ order

Accordingly, the optimal order quantity is as follows:

$$
\begin{aligned}
E O Q & =\sqrt{2 \times D \times O C / H C} \\
& =\sqrt{2 \times 5928 \times 977.34 / 241.80} \\
& =219 \text { units }
\end{aligned}
$$

This computation suggests that the firm should place order for 219 units per order from the supplier in order to minimize cost. This value will be used in the model experimentation to find the reorder point that yields the lowest average total inventory cost per week. 


\section{Model Experimentation}

\section{Simulation for Reorder Points of $\mathbf{5 0 0}$ units to 1000 units}

Since the average weekly demand is 114 units and the longest lead time is 6 weeks, multiplying these two quantities produces an average demand during lead time of 684 units. Accordingly, simulation experiments were run using different values of reorder points in multiples of 50, starting from 500 units up to 1,000 units. The resulting holding cost per week, ordering cost per week, shortage cost per week, and the average total inventory cost per week are presented in Table 3.

Table 3: Simulation Results for Alternative Reorder Points (500 units to 1,000 units)

\begin{tabular}{|l|l|l|l|l|}
\hline $\begin{array}{c}\text { Reorder } \\
\text { Points }\end{array}$ & $\begin{array}{c}\text { Holding } \\
\text { Cost per } \\
\text { Week } \\
\text { (RM) }\end{array}$ & $\begin{array}{c}\text { Ordering } \\
\text { Cost per } \\
\text { Week } \\
\text { (RM) }\end{array}$ & $\begin{array}{c}\text { Shortage } \\
\text { Cost per } \\
\text { Week } \\
\text { (RM) }\end{array}$ & $\begin{array}{c}\text { Average } \\
\text { Total } \\
\text { Inventory } \\
\text { Cost per } \\
\text { Week (RM) }\end{array}$ \\
\hline 500 & 703.66 & 461.30 & 1484.56 & 2649.52 \\
\hline 550 & 854.04 & 483.78 & 844.44 & 2182.26 \\
\hline 600 & 997.07 & 492.58 & 604.39 & 2094.04 \\
\hline 650 & 1140.92 & 504.31 & 269.36 & 1914.59 \\
\hline 700 & 1402.99 & 509.19 & 154.24 & 2066.43 \\
\hline 750 & 1629.78 & 512.13 & 64.16 & 2206.07 \\
\hline 800 & 1857.01 & 513.10 & 40.64 & 2410.75 \\
\hline 850 & 2002.89 & 514.08 & 33.59 & 2550.57 \\
\hline 900 & 2287.01 & 514.08 & 33.59 & 2834.69 \\
\hline 950 & 2514.34 & 515.06 & 29.31 & 3058.72 \\
\hline 1000 & 2748.48 & 515.06 & 27.43 & 3290.96 \\
\hline
\end{tabular}

Table 3 shows that holding cost per week increases as the reorder point is increased from 500 units to 1,000 units. This is expected since larger value of reorder point result in higher average inventory. The shortage cost per week, on the other hand, decreases because more items are on hand to cater to the demand during lead time. However, the ordering cost per week does not exhibit much difference as the reorder point is increased.

The weekly average total inventory costs (the sum of the ordering, holding and shortage cost) for reorder points of 500 units to 1,000 units are lower than the same cost under the current reorder point of 104 units of RM6,905.51. More importantly, the table shows that the reorder point of 650 units yields the lowest average total inventory cost per week. The corresponding cost amounting to RM1914.59 is $72.27 \%$ lower than the cost under the current inventory system. Hence, based on the simulation, this is the best reorder point for the sensor cable. This result is also illustrated in the following Figure 3. 


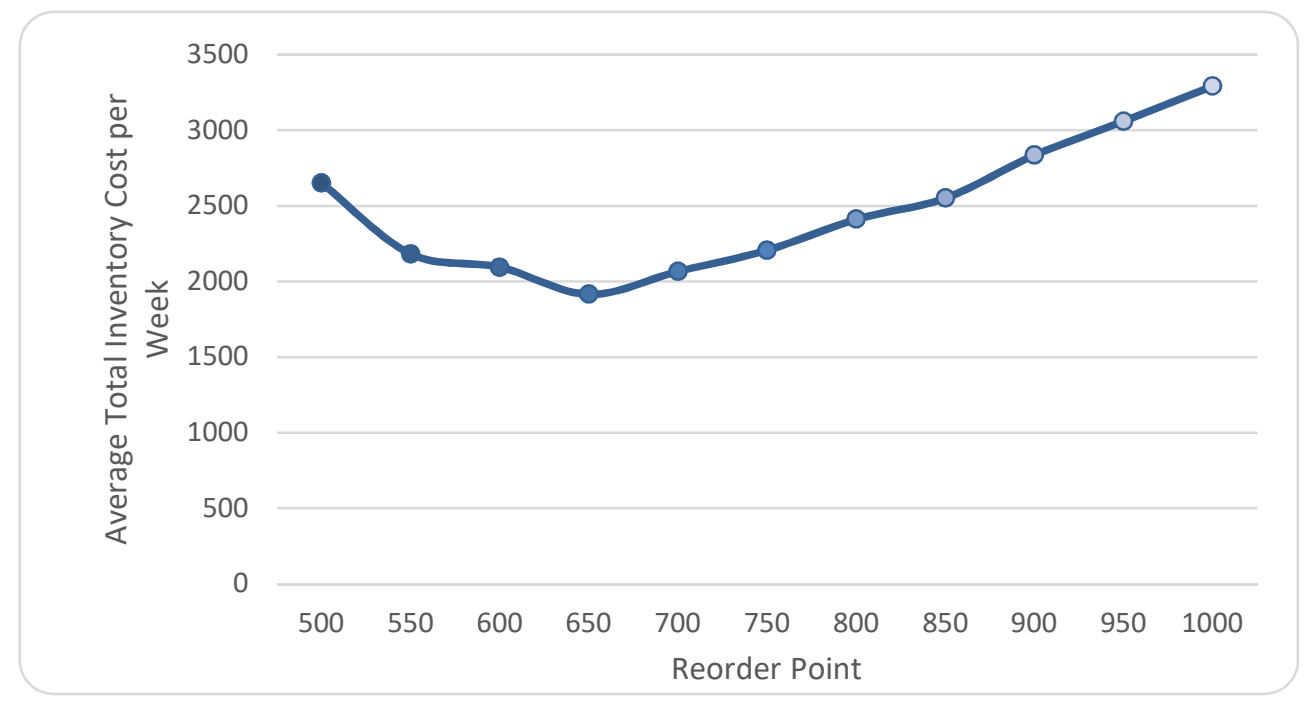

Figure 3: Average Total Inventory Cost per Week for Alternative Reorder Points (500 units to 1,000 units)

\section{Simulation for Reorder Points of $\mathbf{6 0 0}$ units to $\mathbf{7 0 0}$ units}

In previous section, it was identified that reorder point of 650 units generated the lowest average total inventory cost per week. However, the average total inventory cost per week may decrease further between reorder point of 650 units and 700 units. To narrow down on the best reorder point, further simulation experiments were conducted focusing on the inventory costs generated based on reorder points of 600 units up to 700 units, in incremental values of 10 units. The results are given in the following table.

Table 4: Simulation Results for Alternative Reorder Points (600 units to 700 units)

\begin{tabular}{|c|c|c|c|c|}
\hline $\begin{array}{l}\text { Reorder } \\
\text { Points }\end{array}$ & $\begin{array}{c}\text { Holding } \\
\text { Cost per } \\
\text { Week (RM) }\end{array}$ & $\begin{array}{c}\text { Ordering } \\
\text { Cost per } \\
\text { Week (RM) }\end{array}$ & $\begin{array}{c}\text { Shortage } \\
\text { Cost per } \\
\text { Week (RM) }\end{array}$ & $\begin{array}{l}\text { Average Total } \\
\text { Inventory Cost } \\
\text { per Week (RM) }\end{array}$ \\
\hline 600 & 997.07 & 492.58 & 604.39 & 2094.04 \\
\hline 610 & 1033.04 & 496.49 & 498.96 & 2028.49 \\
\hline 620 & 1104.61 & 499.42 & 412.91 & 2016.94 \\
\hline 630 & 1101.42 & 499.42 & 410.01 & 2010.85 \\
\hline 640 & 1130.03 & 502.35 & 324.46 & 1956.85 \\
\hline 650 & 1140.92 & 504.31 & 269.36 & 1914.59 \\
\hline 660 & 1236.35 & 508.22 & 162.04 & 1906.61 \\
\hline 670 & 1224.10 & 507.24 & 191.11 & 1922.45 \\
\hline 680 & 1310.78 & 508.22 & 163.55 & 1982.55 \\
\hline 690 & 1383.20 & 510.17 & 110.96 & 2004.34 \\
\hline 700 & 1402.99 & 509.19 & 154.24 & 2066.43 \\
\hline
\end{tabular}


As mentioned earlier in Table 3, Table 4 also shows that the holding cost per week increases as reorder point increases. However, the shortage cost per week does not exhibit a clear trend, while the ordering cost per week also does not show much difference as reorder point increases. The weekly average total inventory cost decreases as the reorder point is increased from 600 units to 660 units and then it starts to increase with reorder points of 670 units onwards. The reorder point of 660 units results in the lowest average total inventory cost per week at RM1906.61 or $72.39 \%$ lower than the cost based on the current inventory system. The average total inventory cost per week is also illustrated in the following Figure 4. Hence, it can be concluded that based on simulation, the reorder point of 660 units generates the lowest total inventory cost per week.

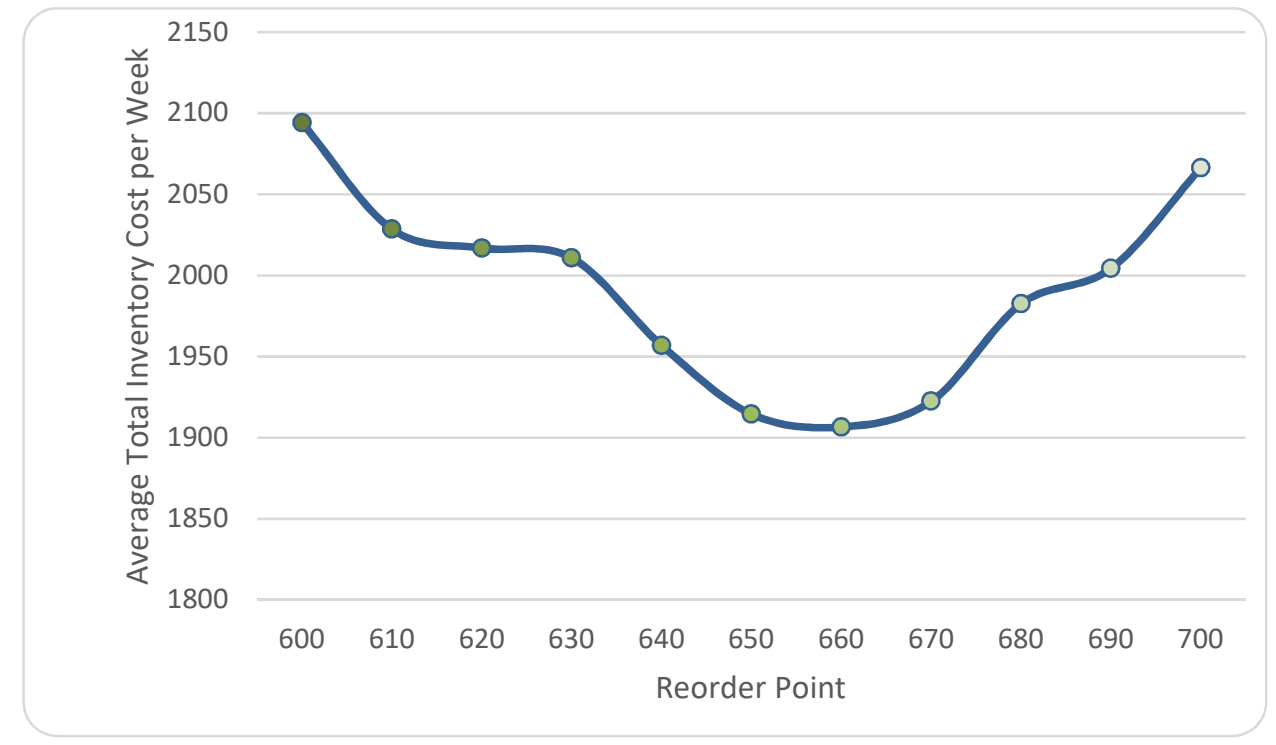

Figure 4: Average Total Inventory Cost per Week for Alternative Points (600 units to 700 units)

\section{CONCLUSIONS}

In this study, simulation experiments were run for 1,000 weeks to study the effect of different values of reorder point. Demand during lead time was used to identify the range of reorder point used in this study. Section 4 presents the results of simulation for reorder point of 500 units to 1000 units with the increment of 50 units. From the simulation models, reorder point of 650 units results in the lowest average total inventory cost per week. Further study was conducted to narrow the search for the reorder point that yields the lowest average total inventory cost per week. This involved reorder points in the range of 600 units and 700 units with the increment of 10 units. From the simulated results, the best reorder point that generates the lowest average total inventory cost per week is 660 units. The economic order quantity formula indicates that the best order size is 219 units. Accordingly, the optimal policy for the manufacturing firm is to place order of 219 units of this item whenever the on-hand inventory is 660 units. The firm could use this new reorder point so that the shortage during lead time can be minimized since more safety stock could be saved. By implementing this reordering policy, it could help to decrease the average total inventory cost per week for this item.

This firm can also use similar approach to determine better reordering policy of other expensive parts. However, better results could be obtained if the company could provide a more detailed, accurate and complete data such as holding costs. 
The results from this research will hopefully help this firm to improve the ordering policy for the sensor cable. More alternatives can be applied in order to search for the optimal average total inventory cost per week. Thus, the model presented in this study may not be suitable to other raw materials. However, the same approach can be used to develop an improved inventory policy. A simulation model can be used to explore appropriate inventory policy that can reduce the cost of operating and holding inventory.

\section{REFERENCES}

Abuizam, R. (2011). Optimization of (s,S) Periodic Review Inventory Model with Uncertain Demand and Lead Time Using Simulation. International Journal of Management and Information Sytems, 15, 67-79.

Al-Harkan, I., \& Hariga, M. (2007). A Simulation Optimization Solution to the Inventory Continuous Review Problem with Lot Size Dependent Lead Time. The Arabian Journal for Science and Engineering, 32, 327-338.

Chang, Y., \& Makatsoris, H. (2001). Supply Chain Modeling Using Simulation. International Journal of Simulation, 2, 24-30.

Heizer, J., \& Render, B. (2011). Operations Management (10 ${ }^{\text {th }}$ Ed.) Pearson.

Jacobs, F. R., \& Chase, R. B. (2010). Operations and Supply Management: The Core (2 ${ }^{\text {nd }}$ Ed.) Irwin McGraw-Hill.

Johnson, J. C., \& Wood, D. F. (1986). Contemporary Physical Distribution and Logistics (3 ${ }^{\text {rd }}$ Ed.) PenWell Publishing.

Kelton, W. D., Sadowski, R. P., \& Sturrock, D. T. (2007). Simulation with Arena (4 ${ }^{\text {th }}$ Ed.) McGraw-Hill.

Law, A. M., \& Kelton, W. D. (2000). Simulation Modeling and Analysis (3 ${ }^{\text {rd }}$ Ed.) McGraw-Hill.

Richardson, H. (1995). Control Your Costs then Cut Them. Transportation and Distribution.

Setamanit, S. (2011). Evaluation of Diverse Inventory Policies Using Simulation and Design of Experiment. Technology Management in the Energy Smart World (PICMET), 1-7.

Setamanit, S. (2010). Using Simulation to Explore the Impact of Inventory Policies on Supply Chain Performance. Technology Management for Global Economic Growth (PICMET), 1-6.

Taylor III, B. W. (2004). Introduction to Management Science ( $8^{\text {th }}$ Ed.). Pearson Education International. 